\title{
Regional Economics in Greece: A Spatial Analysis of Business and Population Dynamics
}

Stella Manika ${ }^{1}, E_{\text {Evenia Anastasiou }}^{2}$

${ }^{\prime}$ Laboratory of Urban Morphology and Design, Department of Planning and Regional Development, University of Thessaly, Volos, Greece.

${ }^{2}$ Laboratory of Demographic and Social Analyses, Department of Planning and Regional Development, University of Thessaly, Volos, Greece.

\begin{tabular}{l}
\hline ARTICLE INFO \\
\hline Article History \\
Received 11 May 2020 \\
Accepted 15 June 2020 \\
\hline JEL Classifications \\
J1, R3
\end{tabular}

Keywords:

Business Demography, Population, Regional Economics, Spatial

Statistics, Global Moran's I, LISA, Greece

\begin{abstract}
Purpose:

The economic crisis has led to a series of transformations of the economic and population base of the contemporary spatial units. The present study aims to highlight the indirect impact of the economic crisis on the operation and spatial footprint of the business network in a region with a slight decrease in its population dynamics in the decade 2001-2011.

Design/methodology/approach:

The methodological approach focuses (i) on the spatial and intertemporal observation of the change in the spatial footprint of the businesses and population of Greek Regional Units and (ii) in the identification of spatial clusters with similar behavior of business establishments or deletions (hot-cold spots). For the delineation of the profile of the spatial units, business demography indicators were created, while the analysis was based on spatial statistics methods and spatial autocorrelation indicators, such as the Global and local Moran's I. The panel data used for the present study relate to the establishment and deletions of businesses' during the period 2008-2018 as well as the population Censuses 2001-2011.

Findings:

It is evident that the crisis left its footprint in the Greek periphery. Examining the business network of two Greek Regional Units it is shown that during the crisis period a significant part of the businesses opened ceased in the early years after. Moreover, until 2016 there is a negative balance between business births and deaths. Especially Volos and Skiathos, despite that they presented an increase in their population, show higher intensity of businesses' deaths until 2014 than those of the establishments; after 2015 it is observed an inverse trend with positive establishments balance. The most important finding that confirms that space is not neutral is the autocorrelation in death rates in neighboring municipalities with simultaneous population decline.

Research limitations/implications:

The dependence of the external boundaries of a spatial entity on a neighboring one contributes to the possible effect on spatial patterns. In the present study, the spatial autocorrelation of the establishments and deletions of the businesses of Magnesia and the Sporades was examined, however, the influence of the adjacent area (the Regional Units of Larissa and Fthiotida) was not taken into account due to non-availability of the necessary data.

Originality/value:

The present study contributes to theory by highlighting the impact of the economic crisis in the footprint of a regions' business ecosystem. The added value lies in the connection and dependence of regional economies and populations with space. Future research could build on this study by examining business behavior in other spatial units. Furthermore, this study could be additionally used by policymakers to potentiate awareness of the local development, revitalization, and depopulation challenge.
\end{abstract}

\section{Introduction}

The economic crisis of 2008 decisively affected the Greek area, leaving its mark on the economic stability of Greece and subsequently on its demographic processes. At the same time, significant transformations of land use, socio- 
demographic, and socioeconomic composition of the population occurred. In particular, the residential structure and organization of the medium-sized urban centers (Manika, 2018) and the structure of the rural area (Anastasiou \& Duquenne, 2017) were redefined, as expected in areas that encounter conditions of economic instability (Silverman, Yin and Patterson, 2013). The way in which the economic crisis is perceived in the urban space is mainly a consequence of both its intensity and the individual characteristics of the spatial units that are called upon to deal with it.

Although most research on the spatial imprint of the crisis focuses on the urban space or at the state level, its analysis at the regional or municipal level can significantly enrich the study of this phenomenon. Moreover, the methodology presented may be a useful tool for policymakers especially promoting the reduction of inner - territorial differences (Gubanova \& Voroshilov, 2019). Understanding the situation or factors of the transformation of the economic identity of cities or regions affected by the economic crisis can help governments select the appropriate policies to regenerate and revitalize these areas. These policies may focus among others on economic, social or environmental terms (i.e. green economy investments (Klasinc, 2015)), or a combination thereof.

This paper is structured in four basic sections. The first section deals with the literature review and is the basis of the research questions posed. The second section presents in detail the data used. Along with the data, the methodology that is applied and the way it is adopted in the context of our research are analyzed. The results of the research are presented in the next section, while the paper comes to an end with the analysis of the conclusions and perspectives of the research for its utilization and further development.

\section{Review of Literature}

The spatial footprint of the economic crisis is first and foremost perceived in the building reserve, whether this reserve is intertwined with housing or commercial use. After all, the economic downturn has led to a reduction in the demand for housing, thereby reducing rents and real estate prices, affecting homeowners and their neighborhoods as a whole. This unobstructed availability of real estate is often associated with the disintegration and decline of a structured web.

Utilizing these "non-productive" spaces (Newman and Kim, 2017) can help improve the surrounding area (Cohen, 2001) and promote its development. Non-productive areas are defined as areas that, despite being the basis of several developmental, cultural, or ecological policies, remain empty or abandoned (Newman and Kim, 2017). Nonproductive spaces can be unstructured, green, abandoned industrial facilities, or generally abandoned shells. The total number of these spaces is constantly increasing, culminating in the period following the global economic crisis of 2008 (Mallach, 2012). Although inactive spaces are very often accompanied by a negative label, it is important to mention that depending on their management and potential utilization they can be powerful mechanisms, as shown in Table 1.

Table 1: Potential challenges of inactive urban areas

\begin{tabular}{ll}
\hline Potential challenges of inactive urban spaces & Relevant Literature \\
\hline $\begin{array}{l}\text { A powerful mechanism for new uses } \\
\text { (especially in the case of green spaces) }\end{array}$ & $\begin{array}{l}\text { (Frazier \& Bagchi-Sen, 2015) } \\
\text { (New al., 2018) } \\
\text { (Freestone \& Nichols, 2004) } \\
\text { (Bowman \& Pagano, 2004) }\end{array}$ \\
\hline Improving social cohesion (as for example & (Capdevila, 2014) \\
community gardens or coworking places) & (Tranel \& Handlin, 2006) \\
\hline Crime monitoring or declining & (Kondo et al., 2016) \\
\hline Source: authors' compilation &
\end{tabular}

From the range of non-productive spaces, we have chosen to study the empty stores, in particular the deletions of businesses. It is a fact that trade is one of the dominant sectors of the Greek economy; the stores of wholesale and retail trade, accommodation and catering services and arts, entertainment, and recreation, have a primary role in the economic identity of rural units and contribute significantly to its development, vitality (Mehta, 2007), (Long and Huang, 2017), and economic performance especially when these businesses are small and operate as magnets of urban growth.

Nevertheless, in the effort to quantify the performance of the effects of the economic crisis in the urban space, the timeless study of the location of businesses and its changes or otherwise the demography of businesses is of high importance. Business study or business demography can be a tool for spatial urban analysis, as it can identify the landscape (Brown, 1993) and determine the robustness, or otherwise liveliness, of an area. It is found in the terms business demography, the demography of the firm or firmography and is a new scientific discipline that first appeared 
in the early 20th century (Markowicz, 2014) and examines the structure and composition of all businesses as well as its changes over time (Froment, 2015). It was also used in the Dutch statistical authority, with the term economic geography (Van Wissen, 2002).

Table 2: Meanings and concepts adopted during the spatial study of businesses

\begin{tabular}{ll}
\hline Concepts & Relevant Literature \\
\hline Retail Location Theory & (Brown, 1993) \\
Business Demography & (Markowicz, 2014) \\
Demography of the Firms & (Wissen, 2005) \\
& (Giannetti \& Velucchi, 2006) \\
Firmography & (Maoh \& Kanaroglou, 2013) \\
& (Mejia-Dorantes \& Martín-Ramos, 2013) \\
Mobility of firms & (Froment, 2015) \\
\hline
\end{tabular}

Source: authors' compilation

Eurostat (Eurostat, 2008) and the European Commission (European Commission, 2014) use the term "business demography" to describe the percentages of business establishments, their deletions, the percentage of active businesses, their building facilities and their movements within the city or periphery complex as a whole, an indicator of the dynamics of the businesses for the specific branch of economic activity, the specific spatial unit or the economic status of each country.

The metaphorical use of the term demography for the business study is often used as significant parallels are found in the mechanisms that cause changes in business as a result of beginnings - establishments and deletions mortality, aging or even internal changes in former monopolies (Van Wissen, 2002). There is also a direct correlation between the way businesses and demographic populations are studied, using in both cases theories from other scientific fields such as economics, sociology, and geography (Van Wissen, 2002). In any case, the parallelism of the correlation of the population of individuals with that of businesses stops at the impossibility of substantial and objective determination of the maximum period during which a company is active in the labor market (Markowicz, 2014).

\section{Data and Methodology}

\subsection{Data}

The Regional Units of Magnesia and Sporades were selected to be studied as they represent a wide range of economic activities and demographic characteristics. Indicative of the demographic changes of the specific regional units (Table 3 ) is population changes based on the last two censuses (2001 and 2011). It is obvious that the medium and small residential areas show greater resilience, durability, and flexibility, in terms of their population changes compared to other settlements, due to their potential nature. This nature is explained by the character and structure of Greek society, for which much of the inhabitants of smaller cities have incomes from many different sources (agricultural activity alongside main employment) or even financial dependence on other members of their family, so it was not as strongly affected by economic instability as the inhabitants of the larger residential areas as it did not have to move in search of work.

Table 3: Population changes in municipal units (2001-2011)

\begin{tabular}{llllr}
\hline \multirow{2}{*}{ Municipality } & Municipal Unit & $\begin{array}{l}\text { Population } \\
\mathbf{2 0 0 1}\end{array}$ & $\begin{array}{l}\text { Population } \\
\mathbf{2 0 1 1}\end{array}$ & $\begin{array}{r}\text { Change } \\
\text { (\%) }\end{array}$ \\
\hline \multirow{6}{*}{ Volos } & Volos & 85001 & 86046 & 1,2 \\
& Agria & 5835 & 5632 & $-3,5$ \\
& Esonia & 3059 & 3249 & 6,2 \\
& Artemida & 4397 & 4145 & $-5,7$ \\
& Iolkos & 2081 & 2138 & 2,7 \\
& Makrinitsa & 7538 & 7513 & $-0,3$ \\
& Nea Ionia & 32979 & 33815 & 2,5 \\
\multirow{3}{*}{ Almyros } & Portaria & 2033 & 1911 & $-6,0$ \\
& Almyros & 13198 & 12678 & $-3,9$ \\
& Anavra & 595 & 584 & $-1,8$ \\
& Pteleos & 2648 & 2485 & $-6,2$
\end{tabular}




\begin{tabular}{|c|c|c|c|c|}
\hline & Sourpi & 3698 & 2867 & $-22,5$ \\
\hline \multirow{2}{*}{$\begin{array}{l}\text { Zagora- } \\
\text { Mouresi }\end{array}$} & Zagora & 3759 & 3334 & $-11,3$ \\
\hline & Mouresi & 2690 & 2475 & $-8,0$ \\
\hline \multirow{5}{*}{ South Pelion } & Argalasti & 1998 & 1985 & $-0,7$ \\
\hline & Afetes & 1754 & 1746 & $-0,5$ \\
\hline & Milies & 3100 & 3085 & $-0,5$ \\
\hline & Sipiada & 2180 & 2047 & $-6,1$ \\
\hline & Trikeri & 1713 & 1353 & $-21,0$ \\
\hline \multirow{3}{*}{ Riga-Feraios } & Feres & 6210 & 5752 & $-7,4$ \\
\hline & Karla & 5040 & 4747 & $-5,8$ \\
\hline & Kerarmidi & 580 & 423 & $-27,1$ \\
\hline Skiathos & Skiathos & 5788 & 6088 & 5,2 \\
\hline Alonnisos & Alonnisos & 2425 & 2750 & 13,4 \\
\hline Skopelos & Skopelos & 4706 & 4960 & 5,4 \\
\hline \multicolumn{2}{|c|}{$\begin{array}{l}\text { Regional Units of Magnesia and } \\
\text { Sporades }\end{array}$} & 205005 & 203808 & $-0,6$ \\
\hline
\end{tabular}

Source: ELSTAT. 2011, authors' compilation

The panel data used are derived from the Chamber of Commerce of Magnesia and concern the businesses of all sectors of economic activity. The spatial scale of the analysis is the Kallikratis municipalities of the Regional Units of Magnesia and Sporades in the period 2008-2018. The year 2008 was used as the starting point for the analysis as the effects of the economic crisis had not yet become evident on the economic basis of most Greek spatial units. Therefore, this year's picture (financially and demographically) can be the basis for timeless monitoring and comparison. The panel data provides information about businesses establishment date, the start address or the current address (if it differs from the establishment address), the economic sector, and the deletion date (if occurred) for each municipality.

\subsection{Methodology}

The proposed methodological framework is based on two main pillars. The first concerns the capture of the order of magnitude and the changes in the economic base of the study area both over time (2008-2018) and spatially. The second pillar concerns (i) the exploration of spatial relationships and (ii) the identification of spatial clusters, with similar behavior of establishments and write-offs of businesses (hot-cold spots) or spatial outliers.

In order to outline the economic profile both at the level of the Regional Unit and the level of municipalities, the principles of business demography and descriptive statistics are adopted. The analysis includes the creation of a double-entry matrix $(11 \times 12)$ of the establishments and deletions of businesses in the period 2008-2018. This allows the recording of developments in the balance of businesses in the study area during the economic crisis.

\subsubsection{Business Demography Indicators}

The results produced by the double-entry matrix were the basis for the creation of crude birth rates (CBR) (commencement of commercial activity) and crude death rates (CDR) (deletion of commercial activity). Through crude ratios will be examined the contribution of the municipalities to the overall economic base of a study area and the systematic high quota of registrations or deletions of individual municipalities. Crude rates are derived from the ratio of the number of events in the total population, expressed by the following general relationship:

$$
\text { Crude Rates }=\frac{\text { number of events }}{\text { mean total population }}(1)
$$

They are used to describe the intensity of establishments or deletions in a set of businesses by expressing the number of establishments or deletions per 100 businesses, giving information about the frequency of establishments or deletions in the total number of businesses.

The last business demography indicator produced for the present study is the balance between births and deaths.

$$
\text { Balance }=\frac{\text { Births }}{\text { Deaths }}(2)
$$

The balance indicator is used to compare the percentage of new establishments to the deletions over the period $2008-2018$. 


\subsubsection{Spatial Autocorrelation}

The approach of the second issue, the identification of spatial patterns, requires the use of exploratory spatial data analysis (ESDA) methods and in particular spatial autocorrelation analysis. Spatial statistics focus on the nature of spatial data and, based on mathematical and statistical descriptions, drawing conclusions based on an estimate of the distribution of events and spatial statistical measurements (Zhan et al., 2017).

The method of spatial autocorrelation incorporates tests for both the Global and Local statistical index Moran's I. The Global Moran's I index was used to examine the existence of spatial autocorrelation among locations in data with spatial reference. Its mathematical calculation function is based on the Pearson correlation coefficient (Cliff and Ord, 1973) (Moran, 1950):

$$
I=\frac{n \sum_{i}^{n} \sum_{j}^{n} w_{i j}\left(x_{i}-\bar{x}\right)\left(x_{j}-\bar{x}\right)}{\left(\sum_{i}^{n} \sum_{j}^{n} w_{i j}\right) \sum_{i}^{n}\left(x_{i}-\bar{x}\right)^{2}}(3)
$$

where $\mathrm{n}$ is the sum of the spatial units, wij the weights that determine the degree of spatial proximity of the observations and xi the spatial units.

The index ranges from a set of values from -1 to +1 . The values approaching -1 indicate the existence of a strong negative spatial autocorrelation and therefore it is possible to highlight spatial patterns in which the neighboring observations of a variable are expected to follow different types of behavior. When values approach +1 they indicate strong positive spatial autocorrelation and spatial patterns are expected in which the neighboring observations of a variable are expected to follow the same behavior. As long as the index tends to o, it indicates the absence of spatial relation.

\section{Spatial Weights Creation}

The determination of weights is an important part of the methodological approach, as they represent the mathematical structure that evaluates the spatial relationship of a phenomenon or a variable. The method of calculating spatial weights suitable for the data depends on a number of individual factors, including the island and discontinuous character of the study area and non-spatial characteristics, such as population, demographic, social, and economic status (Suryowati, Bekti and Faradila, 2018).

In the case of the study area, the island character (Regional Unit of Sporades) creates a discontinuity in the area. It was also observed that during the decade 2001-2011 (census data) the permanent population showed a decrease. At the same time, the number of people who have moved and changed their place of permanent residency is 21,235 , of which $7,527(35.5 \%)$ have moved within the specific spatial units. Following the above data, it was considered appropriate to calculate the weights based on the k-nearest neighbors.

There is no ideal way to select the right number of neighbors (Fotheringham, A.S., Brunsdon and Charlton, 2002) and for this reason, repeated tests were performed to examine the sensitivity of the value and the importance of the index, reaching the 4 nearest neighbors.

\section{Local Indicators of Spatial Association (LISA)}

A local indicator of spatial association allows assessing location-specific autocorrelation for each location identifying a value's similarity in this location to its neighbors. This allows locating the clusters rather than pertaining to the pattern as a whole and also characterizing the clusters by type of association (Anselin, 1995). The LISA cluster map shows the significant locations classified by the type of association (Table 4).

Table 4: Types of Spatial Autocorrelation

\begin{tabular}{|c|c|c|c|}
\hline \multirow{2}{*}{ Spatial Clusters } & High-High & $\begin{array}{l}\text { Positive spatial autocorrelation for high } \\
\text { values }\end{array}$ & The core of the cluster \\
\hline & Low-Low & $\begin{array}{c}\text { Positive spatial autocorrelation for low } \\
\text { values }\end{array}$ & The core of the cluster \\
\hline \multirow{2}{*}{ Spatial Outliers } & High-Low & $\begin{array}{l}\text { Negative spatial autocorrelation, high } \\
\text { values surrounded by low }\end{array}$ & Individual locations \\
\hline & Low-High & $\begin{array}{c}\text { Negative spatial autocorrelation, low } \\
\text { values surrounded by high }\end{array}$ & Individual locations \\
\hline
\end{tabular}

Source: (Anselin, Syabri and Kho, 2006), authors' compilation

There are two types of associations, spatial clusters, and spatial outliers. The cluster comprises more than just a core but it also encompasses its neighbors, which is the location surrounding it. The spatial outliers concern individual locations, as they are location specific and spatially different from their neighbors. 


\section{Results}

4.1 Statistical analysis of businesses

During the decade 2008-2018, 10,344 businesses were established in Magnesia and Sporades, of which 38\% (3944) were deletions. As a result, a very large amount of newly established companies do not become viable and cease to operate within the first decade of their establishment. In fact, if we examine the establishments per year (Table 5), we discover that a significant amount of these is deletions, either in the same year or within the next two years of their establishment. In addition, more than half of the businesses established in 2008 and 2009 at the end of 2018 no longer existed. Respectively, the businesses that were established during the period 2010-2014 show high percentages of deletions in 2018 (45.5\%, 46.7\%, 39.4\%, and 38.1\% respectively). In the coming years, high deletion rates are declining significantly.

Table 5: Establishment-Deletion Details of Magnesia and Sporades Businesses, 2008-2018

\begin{tabular}{|c|c|c|c|c|c|c|c|c|c|c|c|c|c|}
\hline \multirow[b]{2}{*}{ Establishments } & \multicolumn{13}{|c|}{ Deletions } \\
\hline & 2008 & 2009 & 2010 & 2011 & 2012 & 2013 & 2014 & 2015 & 2016 & 2017 & 2018 & Active & Total \\
\hline 2008 & 57 & 130 & 139 & 91 & 103 & 48 & 47 & 32 & 24 & 15 & 10 & 517 & 1213 \\
\hline 2009 & & 51 & 149 & 109 & 98 & 52 & 40 & 42 & 23 & 17 & 8 & 533 & 1122 \\
\hline 2010 & & & 63 & 123 & 96 & 61 & 54 & 39 & 32 & 20 & 14 & 604 & 1106 \\
\hline 2011 & & & & 83 & 119 & 79 & 97 & 39 & 31 & 23 & 14 & 554 & 1039 \\
\hline 2012 & & & & & 71 & 110 & 75 & 53 & 38 & 24 & 17 & 596 & 984 \\
\hline 2013 & & & & & & 65 & 96 & 85 & 75 & 48 & 16 & 600 & 985 \\
\hline 2014 & & & & & & & 71 & 134 & 62 & 33 & 33 & 542 & 875 \\
\hline 2015 & & & & & & & & 81 & 73 & 46 & 27 & 494 & 721 \\
\hline 2016 & & & & & & & & & 76 & 60 & 36 & 545 & 717 \\
\hline 2017 & & & & & & & & & & 54 & 59 & 662 & 775 \\
\hline 2018 & & & & & & & & & & & 53 & 753 & 806 \\
\hline Total & 57 & 181 & 351 & 406 & 487 & 415 & 480 & 505 & 434 & 341 & 287 & 6400 & 10344 \\
\hline
\end{tabular}

Examining the annual percentage change of the existing businesses (Table 6) it is found that the years during which the economic crisis in Greece presented high levels of financial and political instability are characterized by a simultaneous decline of the business population. Until 2010, the rate of change in existing businesses increased marginally, which confirms the hitherto imperceptible effect of the crisis on the economic fabric. The highest negative changes are located in the years 2010-2011 (-2.5\%), $2011-2012(-2.9 \%)$ and 2012-2013 (-2.9\%), while the decline in the rate of change lasts up to in $2016(-1 \%)$, lower intensity, however. In the following years, the trend is reversed, culminating in the year 2017-2018, where it shows a significant positive change $(1.7 \%)$.

Table 6: Annual changes of Existing Businesses, Establishments and Deletions

\begin{tabular}{cccc}
\hline YEAR & $\begin{array}{c}\text { Annual change of } \\
\text { existing businesses } \\
(\%)\end{array}$ & $\begin{array}{c}\text { Annual change } \\
\text { of } \\
\text { Establishments } \\
\mathbf{( \% )}\end{array}$ & $\begin{array}{c}\text { Annual change of } \\
\text { Deletions (\%) }\end{array}$ \\
\hline $2008-2009$ & 0,24 & $-7,5$ & 1,3 \\
$2009-2010$ & 0,07 & $-1,4$ & 33,5 \\
$2010-2011$ & $-2,4$ & $-6,1$ & 1,4 \\
$2011-2012$ & $-2,9$ & $-5,2$ & $-0,6$ \\
$2012-2013$ & $-2,9$ & 0,1 & $-31,9$ \\
$2013-2014$ & $-0,8$ & $-11,2$ & 0,0
\end{tabular}




$\begin{array}{lccc}2014-2015 & -1,7 & -17,7 & -12,4 \\ 2015-2016 & -1,0 & -0,6 & -15,1 \\ 2016-2017 & 0,2 & 8,1 & -27,1 \\ 2017-2018 & 1,7 & 4,1 & -23,4\end{array}$

Regarding the changes in the establishment and deletion of businesses (Figure 1), Magnesia and the Sporades follow the economic course of Greece. The annual changes of the establishments until 2012 are at high negative levels, de-escalating in 2013, and in 2014 and 2015 they return, doubling the negative rate of establishments. Respectively, in 2009-2010 the number of businesses that were deleted from the registers of the Chamber of Magnesia increased by $33.5 \%$. This change seems to be eliminated two years later (2012-2013) with a corresponding reduction of the deletion rate by $32 \% .2015$ is a milestone for businesses, as the annual valuation of new establishments is positive and at the same time significantly reduces the percentage of deletions.

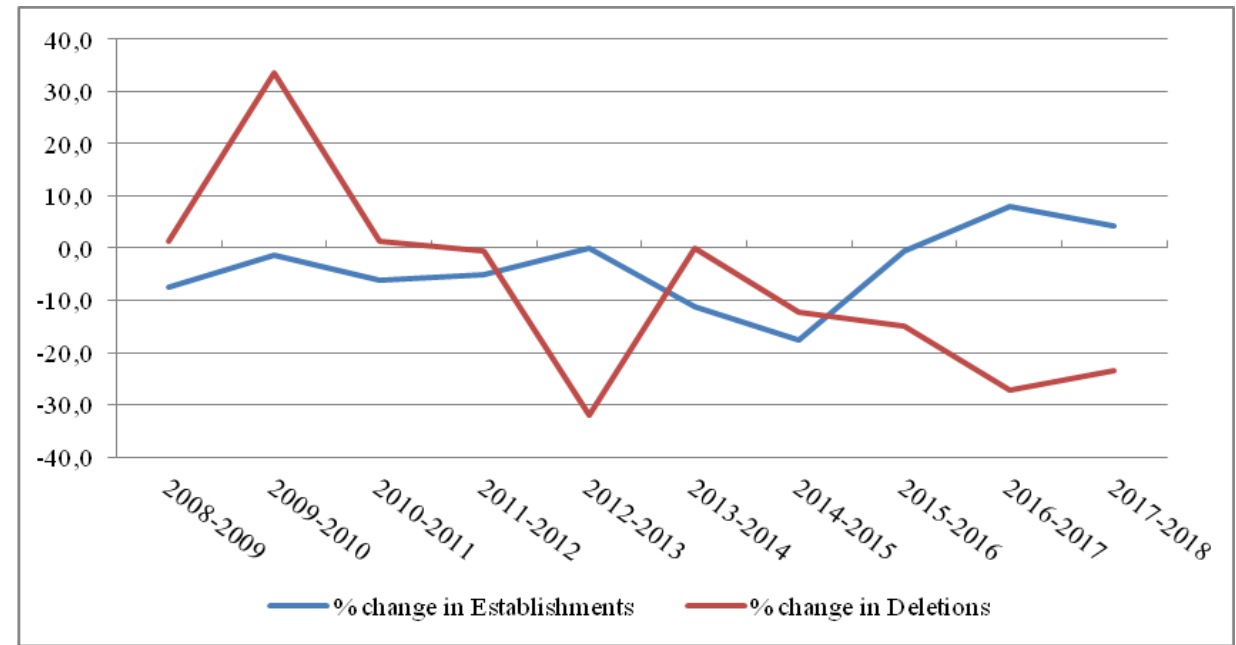

Figure 1: Change of Establishments and Deletions of Businesses, 2008-2018

The business population pyramid (Figure 2) borrows the form and logic of its depiction of the demographics. In the crude birth rate (CBR) the simulated curve follows a slightly declining trend from 2008 to 2012. The significant inflow of new business inflows $(>6 \%)$ is a significant increase in the business population holding up the indices. The downward trend is slightly reversed in 2013 and then follows a downward trend until 2018.

The rise in the crude death rate (CDR) until 2012 suggests an increase in business deletions. The crude index is thus shaped by the increase in deletions while reducing the population of existing businesses. Therefore the base of the pyramid $(2008,2009)$ is wider than the top $(2017,2018)$, as the number of existing businesses decreases during the study period, due to the simultaneous reduction of establishments and increase of deletions. It is important to note that after 2013 the CDR has been steadily declining.

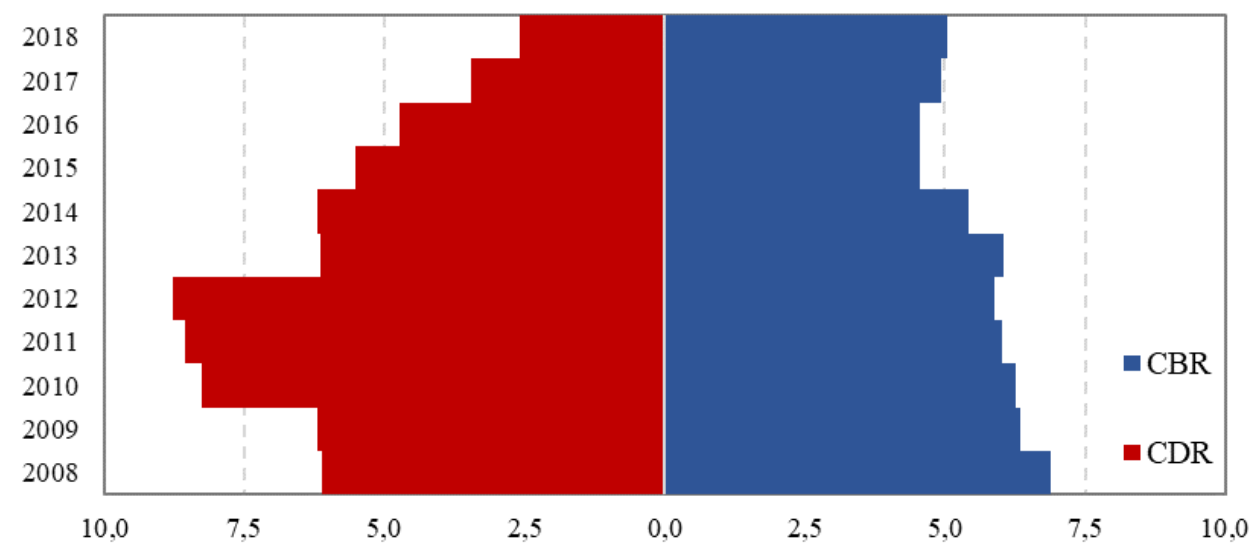

Figure 2: The pyramid of Establishments and Deletions (Crude Rates), 2008-2018 
The balance of establishment-deletions (or births-deaths) from 2008 to 2012 (Table 7) shows a steady decrease, while in 2010 it is the first year that the deletions exceeded the establishments. In 2012 the balance sheet showed the largest imbalance, with 67 businesses being established for every 100 deletions. In 2013 there is a balance, which in the next three years will again receive a negative sign. The situation is changing significantly and the balance captures a very strong and significant change in 2017 (141.6) and 2018 (193.7). Especially in 2018, the percentage of establishing new businesses is twice that of deletions.

Table 7: Demographic indicators of Magnesia and Sporades businesses, 2008-2018

\begin{tabular}{llll} 
Year & CBR & CDR & Balance \\
\hline 2008 & 6,9 & 6,1 & 112,2 \\
2009 & 6,4 & 6,2 & 102,6 \\
2010 & 6,3 & 8,3 & 75,8 \\
2011 & 6,0 & 8,6 & 70,1 \\
2012 & 5,9 & 8,8 & 66,9 \\
2013 & 6,1 & 6,1 & 98,4 \\
2014 & 5,4 & 6,2 & 87,6 \\
2015 & 4,5 & 5,5 & 81,9 \\
2016 & 4,6 & 4,7 & 95,5 \\
2017 & 4,9 & 3,4 & 141,6 \\
2018 & 5,0 & 2,6 & 193,7 \\
\hline
\end{tabular}

\subsection{Spatial Statistical Analysis}

In addition to the analysis of the study area as a whole, Crude birth (CBR) and death (CDR) rates, were calculated on the spatial scale of the Kallikratis Municipalities (Table 8) in order to identify differences in the intensity of establishments and deletions in the individual space. The first finding of the analysis at a lower spatial level is the heterogeneity in the contribution of the municipalities to all businesses of the study area. Both the CBR and the CDR during 2008-2013 presented higher tensions than in previous years. The analysis of the cruse rates also shows that in 2018 the phenomenon of business deletions was severely reduced.

There emerged municipalities systematically characterized by high rates of establishments (such as Volos and Skiathos) throughout, and municipalities with high rates of establishments until 2015 and high decline in 2017 and 2018 (Almyros, Alonissos). Finally, municipalities with medium intensity of establishment are identified until 2012, and significant negative changes in the coming years (Zagora-Mouresi, South Pelion, Riga-Feraios). The intensity of the deletions shows different behavior and consequently, the participation of the municipalities in the whole study area is differentiated. Volos and Skiathos (2010-2014) show high death rates of businesses, whose intensities are stronger than those of the establishments. The municipalities of Riga Feraiou and Alonissos have been characterized by small intensities over time and therefore have a smaller contribution to the whole, a fact that in practice proves the limited tendency of companies to deletion in these municipalities. Finally, in the island municipality of Skopelos in the period 2010-2012, particularly large deletions were detected, but after 2015 they doubled.

Table 8: Crude Birth Rates and Crude Death Rates at municipality level, 2008-2018

\begin{tabular}{llccccccccccc}
\hline $\begin{array}{l}\text { Crude } \\
\text { Rate }\end{array}$ & Municipality & 2008 & 2009 & 2010 & 2011 & 2012 & 2013 & 2014 & 2015 & 2016 & 2017 & 2018 \\
\hline \multirow{2}{*}{ Volos } & 7,4 & 6,6 & 6,1 & 5,7 & 6,4 & 6,5 & 5,9 & 4,8 & 4,6 & 4,9 & 5,0 \\
& Almyros & 6,4 & 8,0 & 7,7 & 4,5 & 5,7 & 7,9 & 6,3 & 4,0 & 3,7 & 2,6 & 2,1 \\
& Zagora-Mouresi & 6,4 & 4,9 & 4,7 & 3,0 & 4,5 & 3,6 & 4,0 & 2,9 & 3,4 & 4,1 & 3,9 \\
CBR & South Pelion & 5,5 & 5,1 & 5,5 & 4,7 & 4,7 & 3,7 & 2,6 & 3,1 & 2,1 & 3,2 & 3,3 \\
& Riga-Feraios & 5,4 & 5,4 & 8,3 & 7,3 & 3,5 & 5,2 & 3,6 & 2,9 & 3,1 & 4,0 & 3,5 \\
& Skiathos & 6,3 & 6,4 & 8,1 & 7,9 & 5,3 & 6,7 & 5,1 & 5,9 & 5,7 & 7,0 & 7,6 \\
& Alonissos & 6,9 & 8,0 & 7,7 & 4,5 & 5,7 & 7,9 & 6,3 & 4,0 & 3,7 & 2,6 & 2,1
\end{tabular}




\begin{tabular}{lllllllllllll}
\hline & Skopelos & 4,4 & 5,6 & 6,9 & 8,2 & 3,8 & 5,2 & 5,0 & 5,3 & 3,8 & 4,8 & 6,6 \\
\hline \multirow{2}{*}{ Volos } & 6,6 & 6,8 & 8,6 & 9,6 & 9,7 & 6,9 & 6,5 & 6,4 & 4,9 & 3,5 & 2,7 \\
& Almyros & 6,1 & 3,4 & 5,4 & 5,0 & 4,5 & 4,8 & 3,3 & 3,0 & 2,8 & 3,2 & 1,4 \\
& Zagora-Mouresi & 4,8 & 3,9 & 5,4 & 5,7 & 5,9 & 5,3 & 5,9 & 4,0 & 2,5 & 2,7 & 2,3 \\
& South Pelion & 4,6 & 4,9 & 7,2 & 5,8 & 5,6 & 3,4 & 3,9 & 3,4 & 4,3 & 3,4 & 1,6 \\
& Riga-Feraios & 5,2 & 5,5 & 8,6 & 7,0 & 6,1 & 4,0 & 6,0 & 3,4 & 4,5 & 2,5 & 2,5 \\
& Skiathos & 5,3 & 5,5 & 7,7 & 7,0 & 7,0 & 4,9 & 4,8 & 3,5 & 5,3 & 3,4 & 3,1 \\
& Alonissos & 5,3 & 3,4 & 5,4 & 5,0 & 4,5 & 4,8 & 3,3 & 3,0 & 2,8 & 3,2 & 1,4 \\
& Skopelos & 4,8 & 3,1 & 9,0 & 7,5 & 8,6 & 4,8 & 5,0 & 3,0 & 3,6 & 2,8 & 1,5 \\
\hline
\end{tabular}

\section{Global Moran's I}

The economic crisis left its spatial imprint on the municipalities of Magnesia and the Sporades and caused transformations in the economic field. The analysis of spatial autocorrelation and the calculation of local indicators for the decade 2008-2018 showed the trends of establishment and deletions of businesses through a series of spatial patterns.

The Global Moran's I index (Figure 3) highlights a significant negative spatial correlation for both the Crude Indicator of Establishments (CBR) and the Crude Indicator of Deletions (CDR), for most years of the study period ( $p$ $<0.05)$. Consequently, the existence of spatial autocorrelation confirms the existence of spatial patterns, as municipalities with similar rates of establishment and deletion tend to be closer to each other. In particular, the differences in the CBR index are particularly small, with the exception of the years 2009, 2014, 2015, and 2018, in which low-intensity spatial autocorrelation is observed. Regarding the CDR, the highest negative autocorrelation was observed in 2010 and 2016, while particularly high intensities occurred during the years 2011, 2012 and 2013 , during which the economic crisis in Greece was not completely controlled and the economic environment was highly unstable.

As can be seen from the data, the deletion of businesses shows higher intensities compared to the establishment during the years 2009-2017, however, they follow the same trend. In 2008 the behavior of the indicators is diametrically opposed, with the CBR showing autocorrelation, in contrast to the CDR where its distribution in the space follows a random pattern, confirming that in 2008 crisis was in a fetal stage and did not affect spatial behavior of deletions. The reverse situation is reflected in 2018, where the post-crisis era seems to be spatially affecting the deletion of businesses in relation to the establishment of new businesses, in which it seems to have little influence.

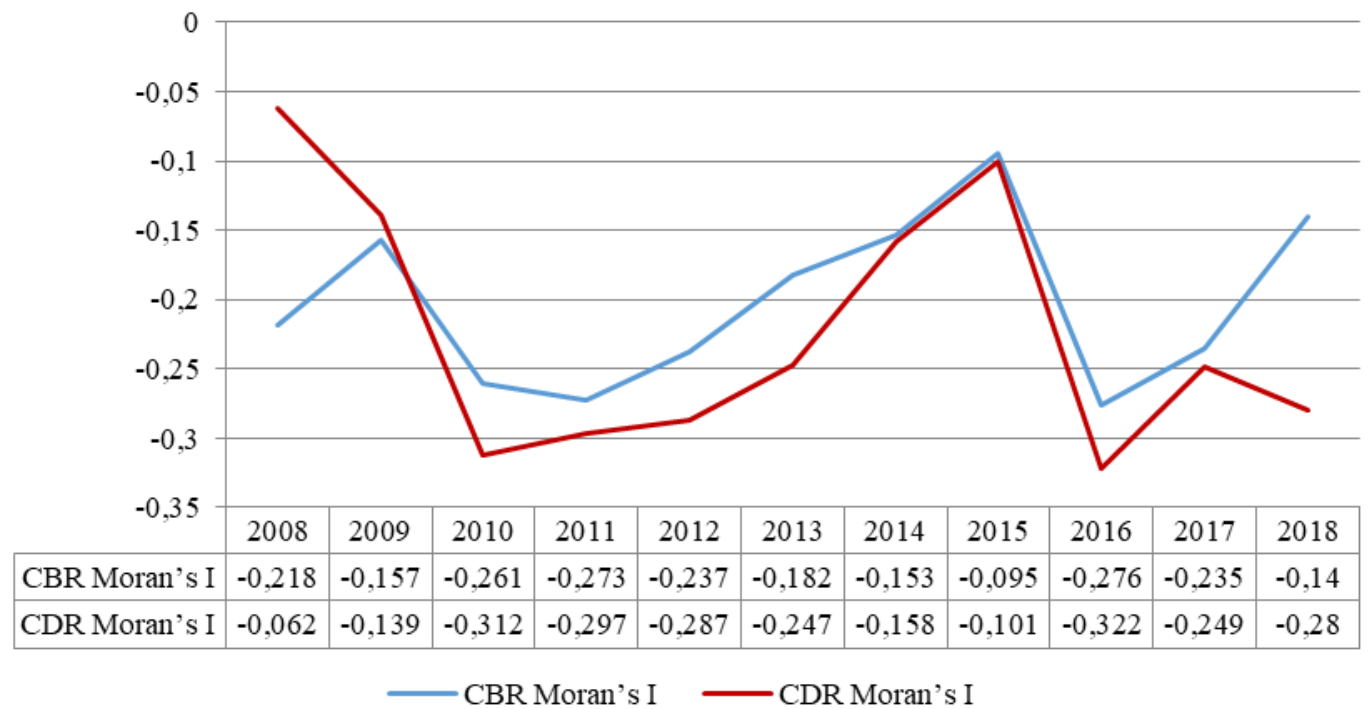

Figure 3: Global Moran’s I Index, Regional Units of Magnesia and Sporades, 2008-2028

\section{Local Moran's I}

In the case of CBR the results do not identify evidence of clustering but spatial outliers (Figure 4). The study area as confirmed by Local Moran's I does not present significant hot or cold spots for the establishments, only 
municipalities that are classified as spatial outliers. The specific spatial patterns are distinguished in five years of the period 2008-2018 and the majority of them are defined as "low-high" type. These are the municipalities of RigaFeraios (2010) ( $p<0.05$ ), Almyros (2013) ( $<<0.05$ ), Volos (2015, 2016) ( $<<0.001$ ), which have low business establishment rates but are adjacent to municipalities with high establishment rates. In 2017, a "high-low" municipality appears in the municipality of South Pelion $(p<0.05)$, with a significant percentage of new businesses, surrounded by cold spots.

Moran's I local indicators for the business death rate (Figure 5) confirm the existence of hot and cold spots across Magnesia and Sporades stores. In 2008, a cold spot was found in Skiathos ( $p<0.05)$, which confirms the existence of a spatial cluster in which the neighboring municipalities have an equally high mortality rate in businesses. The previous pattern ceases to exist in 2009 and is being replaced by a high price hub in the municipality of South Pelion ( $\mathrm{p}<0.05$ ), with a simultaneous appearance of a spatial outlier in the municipality of Zagora-Mouresi $(\mathrm{p}<0.05)$. In 2011 the same municipalities are transformed into spatial outliers $(\mathrm{p}<0.05)$ with low-mortality patterns and spatial proximity to municipalities with high accumulation of deletions. The deletions of businesses in the study area in 2012 and 2013 do not follow any spatial pattern and are obviously distributed randomly, while in 2014 the municipality of South Pelion reappears as a spatial outlier $(\mathrm{p}<0.05)$, creating a "low-high" type pattern. This particular pattern is maintained in 2015 ( $\mathrm{p}<0.001)$, while an additional hot spot is located in the municipality of Zagora-Mouresi ( $\mathrm{p}<0.05)$ confirming the high deletion of businesses in neighboring municipalities. In 2016, a change took place and ZagoraMouresi does not represent a hot spot but is a spatial outlier $(\mathrm{p}<0.001)$ of the "low-high" type. In 2017, a random distribution is made in the area, however, the overall pattern of 2015 reappears, highlighting a source of a high percentage of business deletions in the municipality of Zagora-Mouresi $(p<0.05)$.

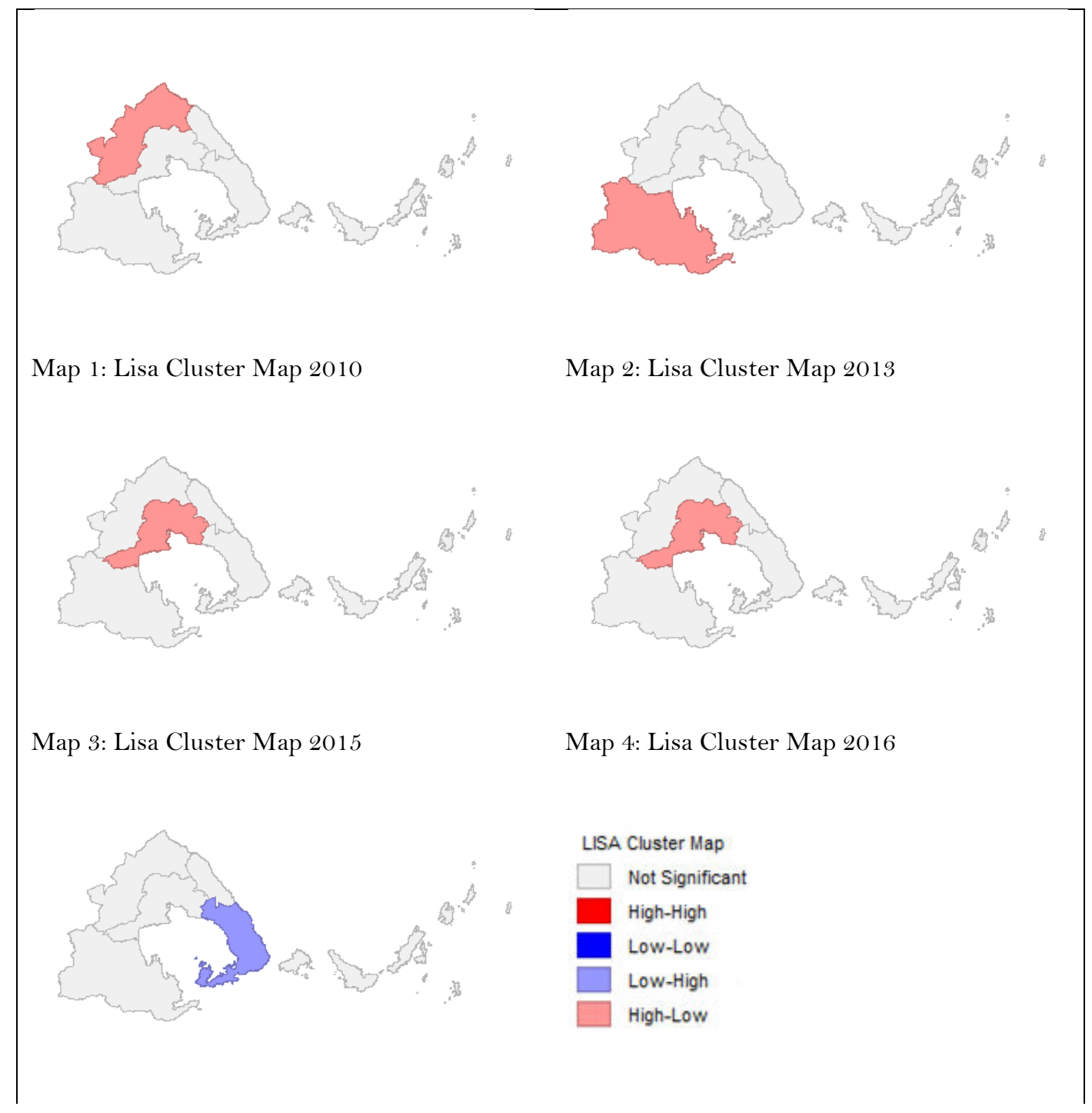

DOI: 10.25103/ijbesar.132.06 


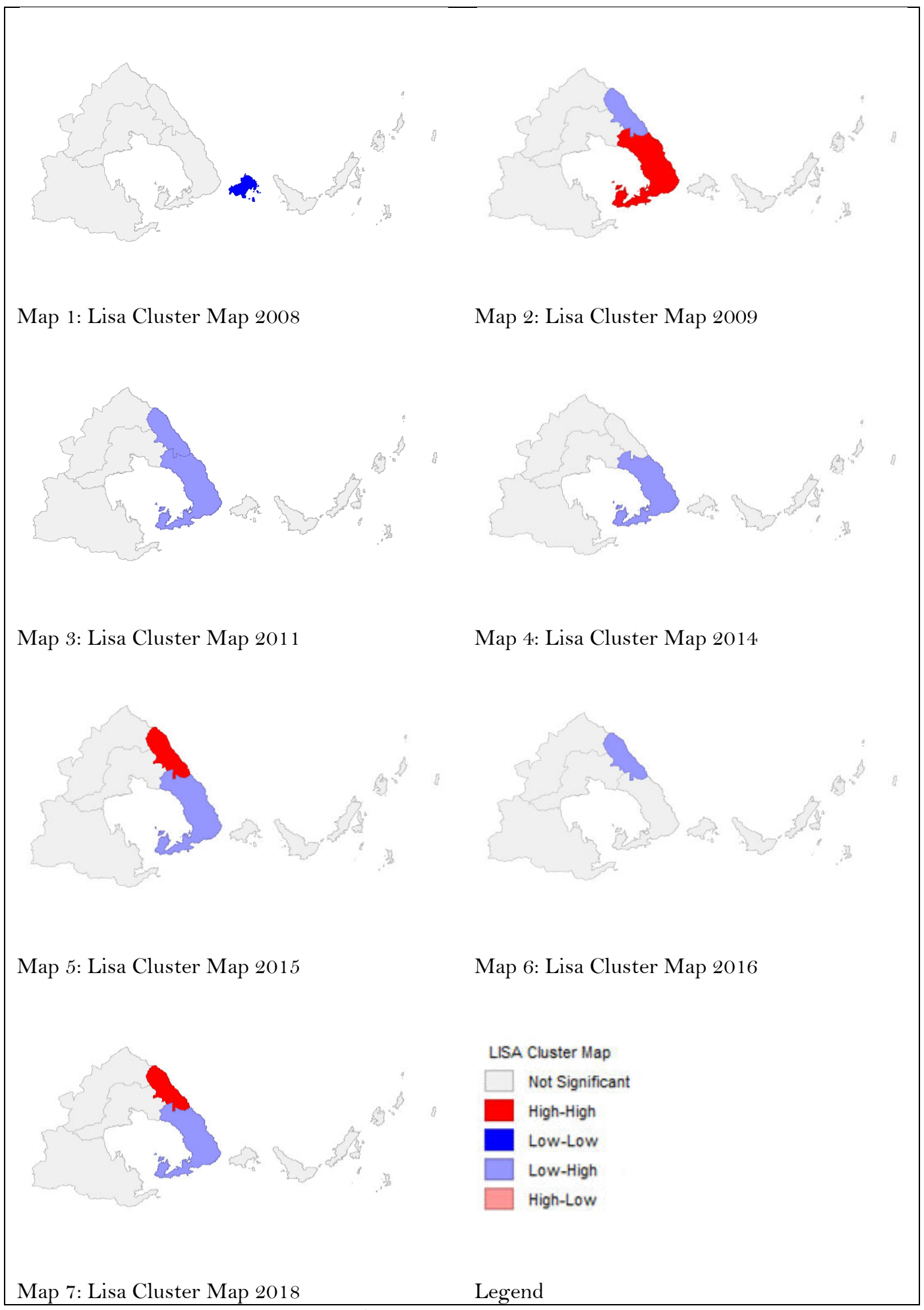

Figure 5: Local CDR Maps

\section{Conclusion and Recommendations}

The economic crisis left its spatial footprint on the municipalities of Magnesia and the Sporades and caused transformations in the economic field. Given that $40 \%$ of businesses established in these Regional Units in the decade 2008-2018 have not survived, it highlights the need to investigate the spatial behavior of establishments and the deaths of businesses.

Spatial analysis of crude indices identified spatial inhomogeneity, especially in terms of the behavior of establishing new businesses during the decade 2008-2018. On the contrary, the deletion of the businesses seems to 
create spatial clusters in the municipalities with a developed tourist sector. In addition, these municipalities contribute with high intensity to the spatial footprint of the economic profile of the Regional Units. Specifically, cold spots are located in Skiathos in 2008, while emerge noticeable spatial clusters with a high death rate in the municipalities of South Pelion (2009) and Zagora-Mouresi (2015, 2018).

However, it must be born in mind that the dependence of the external boundaries of a spatial entity on a neighboring one contributes to the possible effect on spatial patterns. In the present study, the spatial autocorrelation of the establishments and deletions of the businesses of Magnesia and the Sporades was examined, however, the influence of the adjacent area (the Regional Units of Larissa and Fthiotida) was not taken into account due to nonavailability of the necessary data. This constitutes a limitation for the present research, especially knowing that space is not neutral and presents continuity beyond the administrative limits.

The present research sheds the light on the interdependent relationship of space and businesses, as proved by literature review, in practice. The implications of the results may be deployed by local actors to plan strategies for entrepreneurship incentives, revitalization, and attractiveness of a medium-sized regional unit, with both urban and rural populations. Tracing this complex relationship can also help Greek regions become "smarter" and more innovation-oriented (Katimertzopoulos \& Vlados, 2019), with limited corruption levels (Botrić et. al., 2015). In view of the findings mentioned, future research regards further the investigation of the driving forces that triggered the transformations in the business sector of Magnesia and Sporades.

\section{References}

Anselin, L. (1995) 'Local Indicators of Spatial Association-LISA', Geographical Analysis, 27(2), pp. 93-115. doi: 10.1111/j.15384632.1995.tbo0338.x.

Anselin, L., Syabri, I. and Kho, Y. (2006) 'GeoDa: An introduction to spatial data analysis', Geographical Analysis, 38(1), pp. 5-22. doi: $10.1111 /$ j.0016-7363.2005.00671.x

Anastasiou, E., \& Duquenne, M.-N. (2017). The return to the rural in Greece during the last decade: A methodological approach of the potential spatial patterns. In V. Janeska \& A. Lozanoska (Eds.), Fifth International Conference of the Balkans demography: The population of the Balkans at the dawn of the 21st century (pp. 331-354). Institute of Economics - Skopje, Ss. Cyril and Methodius University in Skopje Prolet 1, 1000 Skopje, Republic of Macedonia.

Botrić, V. and Božić, L. (2015) Innovators' vs Non-innovators' perceptions of corruption in European post-transition economies, International Journal of Business and Economic Sciences Applied Research, vol. 8(3), 47-58.

Bowman, A., \& Pagano, M. (2004). Terra incognita: Vacant land and urban strategies, Georgetown University Press, Washington, D.C.

Brown, S. (1993). Retail location theory: evolution and evaluation. The International Review of Retail, Distribution and Consumer Research, 3(2), 185-229. https://doi.org/10.1080/09593969300000014

Capdevila, I. (2014). Knowledge Dynamics in Localized Communities: Coworking Spaces as Microclusters. SSRN Electronic Journal. https://doi.org/10.2139/ssrn.2414121

Cohen, J. R. (2001) 'Abandoned housing: Exploring lessons from baltimore', Housing Policy Debate. Routledge, 12(3), 415-448. doi: $10.1080 / 10511482.2001 .9521413$.

Cliff, A. D. and Ord, J. K. (1973) Spatial Autocorrelation. London: Pion.

Fotheringham, A.S., Brunsdon, C. and Charlton, M. (2002) Geographically Weighted Regression: the analysis of spatially varying relationships. Chichester: John Wiley and Sons.

Frazier, A. E., \& Bagchi-Sen, S. (2015). Developing open space networks in shrinking cities. Applied Geography, 59(0), 1-9. https://doi.org/http://dx.doi.org/10.1016/j.apgeog.2015.02.010

Freestone, R., \& Nichols, D. (2004). Realising new leisure opportunities for old urban parks: The internal reserve in Australia. Landscape and Urban Planning, 68(1), 109-120. https://doi.org/10.1016/j.landurbplan.2003.07.001

Froment, P. (2015). Mobility of firms and territories: Paradoxes of the tangier fashion industry. Annales de Geographie, 701, 31-50.

Giannetti, R., \& Velucchi, M. (2006). The demography of manufacturing firms (1911-1971) (pp. 63-86). Physica-Verlag HD. https://doi.org/10.1007/3-7908-1712-0_4

Katimertzopoulos, F., Vlados, C. (2019). "Towards a New Approach of Innovation in Less Developed Regional Business Ecosystems," International Journal of Business and Economic Sciences Applied Research (IJBESAR), vol. 12(2), pages 33-41.

Klasinc, J. (2015) Investment in green economy as a potential source of value added, International Journal of Business and Economic Sciences Applied Research, vol. 8(3), pages 109-118.

Kondo, M., Hohl, B., Han, S., \& Branas, C. (2016). Effects of greening and community reuse of vacant lots on crime. Urban Studies (Edinburgh, Scotland), 53(15), 3279-3295. https://doi.org/10.1177/0042098015608058

Lee, J., Newman, G., \& Park, Y. (2018). A comparison of vacancy dynamics between growing and shrinking cities using the Land Transformation Model. Sustainability (Switzerland), 10(5). https://doi.org/10.3390/su10051513

Long, Y. and Huang, C. C. (2017) 'Does block size matter? The impact of urban design on economic vitality for Chinese cities', Environment and Planning B: Urban Analytics and City Science, O(O), p. 2399808317715640. doi: 10.1177/2399808317715640.

Mallach, A. (2012) LAYING THE GROUNDWORK FOR CHANGE: Demolition, urban strategy, and policy reform, Brookings Metropolitan Policy Program,

Manika, S. (2018). Economic crisis, Shrinking Greek cities and Urban Regeneration Policies, Uni-versity of Thessaly, Greece.

Maoh, H., \& Kanaroglou, P. (2013). Modelling firm failure: Towards building a firmographic microsimulation model. In Advances in Spatial Science (Vol. 74, pp. 243-261). Springer International Publishing. https://doi.org/10.1007/978-3-642-31779-8_12

Markowicz, I. (2014). Business Demography - Statistical Analysis of Firm Duration. Transformations in Business $\mathfrak{E}^{2}$ Economics, $13(2 \mathrm{~B}(32 \mathrm{~B})), 801-817$.

Martinez-Fernandez, C. and Wu, C.-T. (2007) Shrinking cities in Australia. Adelaide: SOAC.

Mehta, V. (2007) 'Lively Streets:Determining Environmental Characteristics to Support Social Behavior', Journal of Planning Education and Research, 27(2), 165-187. doi: 10.1177/0739456x07307947. 
Mejia-Dorantes, L., \& Martín-Ramos, B. (2013). Mapping the firmographic mobility: a case study in a region of Madrid. Journal of Maps, 9(1), 55-63. https://doi.org/10.1080/17445647.2013.778799

Moran, P. A. P. (1950) 'Notes on continuous stochastic phenomena', Biometrika, 37, 17-23.

Newman, G. and Kim, B. (2017) 'Urban shrapnel: spatial distribution of non-productive space’, Landscape Research. Routledge, 1-17. doi: 10.1080/01426397.2017.1363877.

Newman, G., Park, Y., Bowman, A. O. M., \& Lee, R. J. (2018). Vacant urban areas: Causes and interconnected factors. Cities, 72. https://doi.org/10.1016/j.cities.2017.10.005

Stanley, B. W. (2016). Leveraging Public Land Development Initiatives for Private Gain. Urban Affairs Review, 52(4), 559-590. https://doi.org/10.1177/1078087415579733

Silverman, R. M., Yin, L. I. and Patterson, K. L. (2013) 'Dawn of the Dead City: An Exploratory Analysis of Vacant Addresses in Buffalo, Ny 2008-2010', Journal of Urban Affairs, 35(2), 131-152. doi: 10.1111/j.1467-9906.2012.00627.x.

Suryowati, K., Bekti, R. D. and Faradila, A. (2018) 'A Comparison of Weights Matrices on Computation of Dengue Spatial Autocorrelation', IOP Conference Series: Materials Science and Engineering, 335(1). doi: 10.1088/1757-899X/335/1/012052.

Tranel, M., \& Handlin, L. B. (2006). Metromorphosis: Documenting change. Journal of Urban Affairs, 28(2), 151-167. https://doi.org/10.1111/j.0735-2 166.2006.00265.x

Van Wissen, L. J. G. (2002) 'The demography of entrepreneurs and enterprises', ERSA conference papers ersa02p419, European Regional Science Association.

Wissen, L. (2005). A micro-simulation model of firms: Applications of concepts of the demography of the firm. Papers in Regional Science, 79(2), 111-134. https://doi.org/10.1111/j.1435-5597.2000.tb00764.x

This is an Open Access article distributed under the terms of the Creative Commons Attribution Licence 